\title{
Novos usos e (re)construções da condição fronteiriça amapaense
}

Jadson Luís Rebelo Porto - Docente da Universidade Federal do Amapá (UNIFAP) no Programa de Pós-graduação em Desenvolvimento Regional e Coordenador do Grupo Percepções do Amapá. Email:

Gutemberg de Vilhena Silva - Pesquisador do Grupo Percepções do Amapá e doutorando do Programa de Pós-Graduação em Geografia da Universidade Federal do Rio de Janeiro (UFRJ). Email:

\section{Resumo}

O processo de integração física entre países, assim como mecanismos de cooperação transfronteiriça institucionalizada, está se tornando cada vez mais frequente na América do Sul. Está claro que um dos grandes protagonistas nesse contexto é o Brasil, cuja política tem sido orientada para a implementação de obras estratégicas de envergadura internacional como os corredores bioceânicos, rodoviários e a já recorrente construção de pontes binacionais. Desde meados da década de 1990, a fronteira amapaense tem sido condicionada para uma série de transformações sociais, geográficas e infraestruturais, as quais indicam a construção de novos usos desse território. Essas transformações ampliaram as interações espaciais entre Brasil e França no contexto sul-americano, o que lança bases para novas análises da condição fronteiriça amapaense, reflexões para as quais este artigo visa contribuir. Em um primeiro momento são tecidas algumas considerações sobre a (re)construção da fronteira e da condição fronteiriça; no segundo, aborda-se a organização espacial amapaense e a reestruturação da condição fronteiriça; no terceiro, analisa-se o programa operacional Amazônia e a cooperação na fronteira franco-brasileira para a área de biodiversidade e pesquisa.

\section{Palavras chave}

Amazônia. Amapá. Biodiversidade. Condição Fronteiriça. Organização Espacial. Cooperação Amapá-Guiana Francesa.

\begin{abstract}
The process of physical integration among countries, as well mechanisms of institutionalized boundary cooperation, is becoming each time more recurrent in South America. It is clear that one of the greater protagonist in this context is Brazil, because its political has been oriented for the implementation of strategic work of international capacity like bio oceanic and highway corridors and already the recurrent constructions of bi national bridges. Since 1990's years, the Amapá boundary has been conditioned for a number of social, geographical and structural transformations that indicate the construction of new uses for this territory. Such transformations have increased the space interactions between Brazil and France in the South America context which launch bases for new analyses of the Amapá boundary condition. This paper has the objective of contribution with these new bases of reflection. Based on this reflection, it was elaborated the three topics: The first one explains some reflections on the reconstruction of the boundary and its conditions; The Second one boards on Amapá space organization and restructure the boundary condition; and The Third one analyses the operational program for Amazon and the cooperation in the Brazil and French boundary for the biodiversity and research areas.
\end{abstract}

\section{Key words}

Amazon. Amapa biodiversity. Boundary condition. Space organization. Brazil and French Guiana boundary cooperation. 


\section{INTRODUÇÃO}

Atualmente, um crescente processo de integração física entre países, e mecanismos de cooperação transfronteiriça institucionalizada estão se tornando cada vez mais frequentes na América do Sul. Está claro que um dos grandes protagonistas em tal contexto é o Brasil, cuja política tem sido orientada para a implementação de obras estratégicas de envergadura internacional como os corredores bioceânicos, rodoviários e a já recorrente construção de pontes binacionais.

Desde meados da década de 1990, a fronteira amapaense tem apresentado uma série de transformações sociais, geográficas e infraestruturais que indicam a criação significativa de novos usos desse território (SILVA, 2007). Essas transformações ampliam as interações espaciais ${ }^{1}$ estabelecidas com a Guiana Francesa e permitem uma revisão da condição fronteiriça do norte do Amapá.

Este artigo visa apresentar uma reflexão sobre essas (re)construções da fronteira amapaense, decorrentes da intensificação de investimentos infraestruturais e de fluxos demográficos e de mercadorias para o norte amapaense, ampliando a interação espacial entre Brasil e França no contexto sul-americano

Para isso, este estudo abordará os seguintes tópicos: o primeiro tece algumas reflexões sobre a (re)construção da fronteira e da condição fronteiriça; o segundo, aborda a organização espacial amapaense e a reestruturação da condição fronteiriça; o terceiro, analisa de uma forma bem geral o Programa Operacional Amazônia (POA, 2007) e a cooperação na fronteira franco-brasileira.

\section{A (RE)CONSTRUÇÃO DA FRONTEIRA E DA CONDIÇÃO FRONTEIRIÇA}

O atual Governo Federal brasileiro tem promovido uma retomada do planejamento estratégico e da atuação do país como agente de coordenação de desenvolvimento. Além disso, a elaboração da Proposta de Desenvolvimento da Faixa de Fronteira (PDFF) teve como objetivo oferecer às diversas instâncias governamentais, como a amapaense e também à sociedade brasileira, uma base conceitual e uma agenda concreta de intervenção que permitisse superar a visão da fronteira como "espaço-problema" em favor de uma concepção que privilegia a região como um espaço pleno de oportunidades de desenvolvimento, de união com os países vizinhos e de valorização da cidadania (BRASIL, 2005).

1 As interações espaciais referem-se a um amplo e complexo conjunto de deslocamentos de pessoas, mercadorias, capital e informação sobre o espaço geográfico (CORRÊA, 1996). 
A fronteira brasileira é uma das áreas estratégicas menos conhecidas do país, apesar de ter sido a primeira a ser oficialmente reconhecida como tal. Sem dúvida, o interesse estratégico da área provém, primordialmente, da imposição de defesa do perímetro de um vasto território ainda pouco povoado e insuficientemente articulado.

A área de fronteira é um espaço que exige concomitância de múltiplos tipos de ação, do tempo curto dos sistemas de vigilância e defesa e do tempo longo da arquitetura da cidadania e da integração dos povos fronteiriços (MACHADO, 2005). Cada um desses propósitos demanda posturas variadas e envolve diversos atores e níveis de decisão, a partir de uma ação intencional, com objetivos a serem alcançados.

A área de fronteira, segundo Machado (2005), apresenta algumas condições associadas a ambientes complexos. Nesse espaço, do ponto de vista cultural, encontramos condições geralmente restritas às camadas mais privilegiadas da população metropolitana: o cidadão fronteiriço, além de ser com frequência bilíngue, beneficia-se do ambiente multicultural característico de uma existência transnacional.

Frequentemente caracterizada de forma negativa por causa dos tráficos ilegais, a mobilidade transfronteiriça da população gera uma experiência acumulada de anos de relacionamento e intercâmbio econômico, social e político com as populações do outro lado do limite internacional, uma experiência a que os próprios atores-cidadãos, imersos no cotidiano, atribuem pouco valor, porém que é essencial para a formulação dos problemas que dificultam a integração sul-americana.

Um aspecto relevante na fronteira internacional da Amazônia brasileira diz respeito a sua gigantesca dimensão territorial. É justamente por essa dimensão, acrescida à sua frequente permeabilidade, legal e ilegal, que tem provocado a necessidade de o poder central conhecer a dinâmica por que passam as cidades fronteiriças.

O debate sobre fronteiras é amplamente realizado por geógrafos, cientistas políticos, juristas, entre outros pesquisadores. Variados também têm sido os significados a elas atribuídos como bem lembra Foucher (1991) e Arbaret-Schulz et al. (2004). Estes últimos, ao proporem uma leitura atualizada de estudos fronteiriços, enfatizam que os recortes territoriais podem ser pensados como pontos de passagem, linhas de demarcação, porção territorial (zona) e fronteirarede. Este trabalho enfocará a última.

Por ser um produto historicamente construído, reestruturado e ressignificado, a condição fronteiriça é constantemente (re)inventada. Isto quer dizer que a cada momento histórico ela é refeita à medida que se constitui em um produto social e politicamente estabelecido. Assim, a condição fronteiriça é um 
Jadson Luís Rebelo Porto • Gutemberg de Vilhena Silva

espaço de diálogo e/ou de conflitos em processo; é lócus de políticas territoriais objetivando a manutenção da soberania em sentido amplo e a articulação econômica em um contexto geopolítico de fluidez comercial a partir das redes geográficas, que utilizam a atual condição fronteiriça como forma de conexão entre territórios mais vastos.

\section{A ORGANIZAÇÃO ESPACIAL AMAPAENSE E A REESTRUTURAÇÃO DA CONDIÇÃO FRONTEIRIÇA}

Para analisar as dinâmicas que influenciaram a organização do espaço amapaense, é preciso considerar diversos fatores, com destaque para: i) a conectividade com as escalas regional e global (LIMA; PORTO, 2008); ii) a influência institucionalgovernamental (PORTO, 2003), iii) a instalação de unidades de conservação (BRITO, 2003; PORTO, 2006); iv) a questão fundiária (LIMA, 2004); v) a reestruturação do uso do território com a retomada do potencial mineral a partir da utilização de novas tecnologias em áreas já exploradas, bem como em função da aproximação BrasilFrança por meio de suas fronteiras físicas a partir da ligação Amapá (BR) - Guiana Francesa (FR) (SILVA, 2008; SILVA; RUCKERT, 2009).

A atual condição fronteiriça tem ocasionado o aparecimento de novos conflitos, com reflexos dos mais variados, seja na escala do vivido, em que se enquadram, por exemplo, os catraieiros, hoteleiros e turistas, seja em escalas intermediárias e até mesmo em uma escala planetária. É importante notar que, no reordenamento dos Estados-nacionais que se seguiu à globalização, ou seja, na mencionada escala planetária, ocorre uma relativização das estratégias de estudo para áreas de fronteira.

Segundo Jessop (2004, p. 28), as escalas geográficas relacionadas às fronteiras relacionam-se em hierarquias crescentemente complexas e engendradas com diversas temporalidades e espacialidades, em vez de em hierarquias em forma simples, umas com as outras. Existem, conforme o autor, formas escalares básicas para se pensar os territórios transfronteiriços na globalização. Uma delas é a análise desses territórios de forma transversal.

Esse tipo de escala é adequado para o estudo de territórios transfronteiriços como o Estado do Amapá, já que neste ocorrem tanto intervenções externas diretas (empresas transnacionais), quanto ações oriundas das empresas que direcionam sua produção, em grande escala, para exportação.

Desde o final do século XIX existe interação econômica entre o Amapá e a Guiana Francesa, quando a atividade pecuária na região dos lagos amapaense (atualmente composta pelos municípios de Amapá, Pracuúba e Tartarugalzinho) garantia alimento à atividade de exploração mineral na Guiana Francesa. No final 
do século XX e primeiro decênio do século XXI, essa interação foi estimulada mediante a implantação e/ou modernização de Sistemas de Engenharia naqueles dois recortes territoriais.

Analisando-se os novos usos da fronteira amapaense, considerando o período de 1995-2009, verificou-se que esses novos usos decorrem, de forma geral, das seguintes ações:

- a assinatura do Acordo-Quadro com a Guiana Francesa (1996), com base nos diálogos havidos no ano anterior, que estimulou a mobilidade demográfica para o Amapá em razão das expectativas criadas pela acessibilidade à essa Unidade Ultramarina Francesa, e ampliou as ações para a interação na fronteira francobrasileira;

- a ampliação do Porto de Santana (1996), que aumentou o fluxo de mercadorias para o Estado do Amapá e tornou possível (e essa tendência existe) o uso do porto para o transporte de equipamentos via Amapá para a Guiana Francesa e, mais especificamente, para a base espacial de Kourou;

- a criação do PARNA do Tumucumaque em 2002 (Figura 1), que aumentou a restrição do uso do espaço amapaense (58\% do espaço amapaense, até então, eram Unidades de Conservação e Reservas Indígenas) e dos municípios por ele abrangidos, estimulando a urbanização do Estado em função das restrições e o debate sobre as Zonas-Tampão na fronteira;

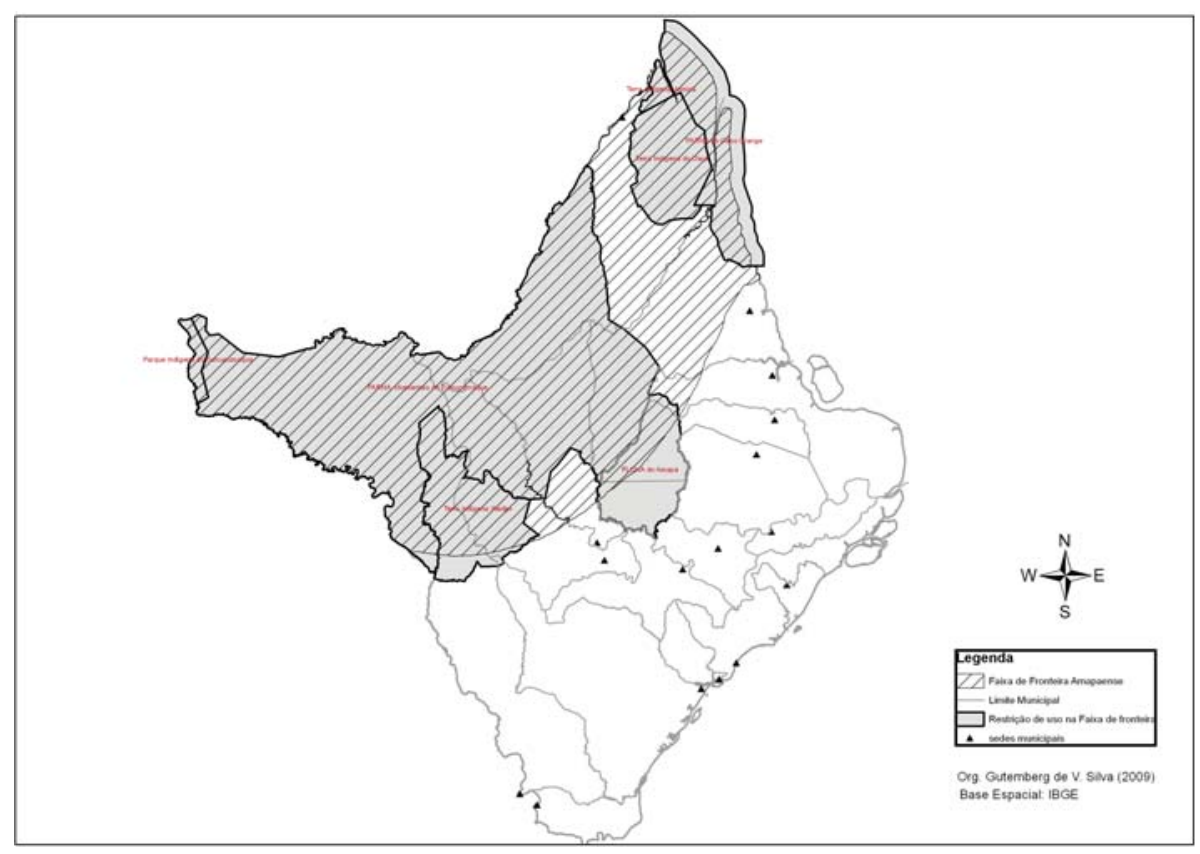

Figura 1 - Áreas com restrição de uso da terra amapaense na Faixa de Fronteira 
Jadson Luís Rebelo Porto • Gutemberg de Vilhena Silva

- a pavimentação da BR-156 (Figura 2), entre 2005 e 2009, que dinamizou a mobilidade demográfica e de mercadorias em direção à fronteira setentrional amapaense;

- a criação da Floresta de Produção do Amapá (2007), que trouxe novas expectativas de uso do território nas terras repassadas do Governo Federal ao Estado do Amapá;

- a perspectiva de construção da Ponte Binacional (Figura 2) para o ano de 2010, que ampliará o grau de integração e interação espacial entre o Amapá e o norte da América do Sul, em especial a Guiana Francesa, que é representante da União Européia no subcontinente.

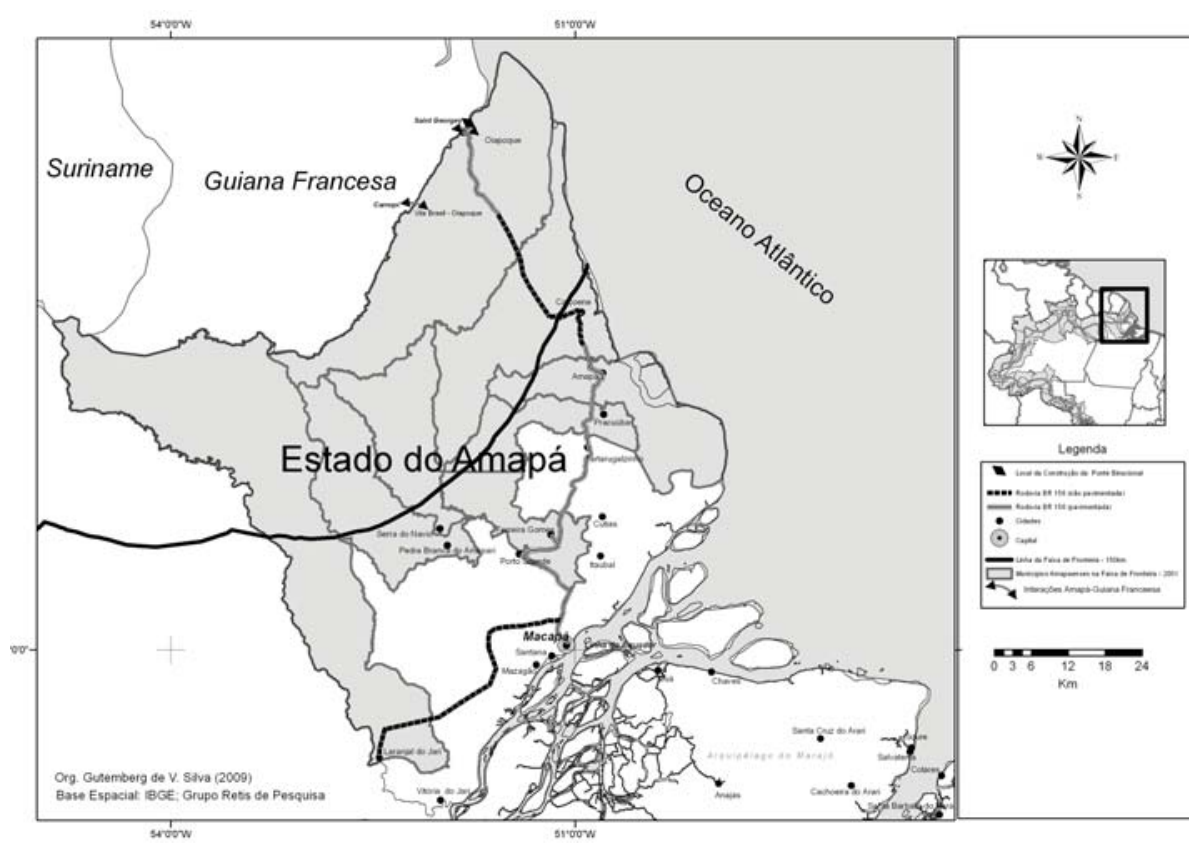

Figura 2 - Municípios amapaenses na Faixa de Fronteira

O contínuo processo de des/reconfiguração do espaço amapaense obedeceu às orientações estabelecidas e socialmente elaboradas pelos poderes públicos e privados, externos às dinâmicas locais, instalando próteses jurídicas, tecnológicas e institucionais capazes de impor novos ritmos de uso do território. É nesse conflito entre o externo e o interno nas relações sociais de engenharias de poder ali estabelecidas que os dilemas territoriais são expressos e se manifestam.

A nova configuração territorial amapaense implica rever a sua condição fronteiriça, a sua atuação na defesa da faixa de fronteira e a sua inserção na economiamundo. Além do fato de ter mais da metade de seu perímetro territorial localizado na 
faixa de fronteira (Figura 2), o desenvolvimento do Amapá é condicionado também pelos seguintes aspectos: i) localização geográfica; ii) suas extensas áreas protegidas e preservadas; iii) a forte participação do capital estrangeiro na exploração de seus recursos naturais; iv) a instalação de regimes aduaneiros especiais; v) as expectativas suscitadas pelas obras do Programa de Aceleração do Crescimento (PAC) do Governo Federal brasileiro e sua articulação com o programa de Integração da Infraestrutura Regional Sul-Americana (IIRSA2), parte integrante da construção de um país competitivo.

A condição fronteiriça amapaense é decorrente de, pelo menos, três fatores: a participação do Governo Federal que criou condições para a mobilidade e reprodução do capital, a articulação das redes criadas/construídas em um espaço poroso e a atuação do capital internacional na exploração de commodities, com o estímulo do Estado, e no atual uso do território fronteiriço.

Esses fatores integram uma gama de relações complexas que propiciam a instalação, na fronteira amapaense, de mecanismos de (des)construção espacial. Sendo a fronteira um espaço de oportunidades onde o ilegal e o legal convivem cotidianamente, aproveitando-se da porosidade característica do espaço, os movimentos materiais e simbólicos expressam-se em constante mutação, razão pela qual se manifestam conflitos em diferentes escalas. É bom lembrar que, no caso de haver conflito, há a possibilidade de ele vir a ter caráter internacional.

Assim sendo, a condição fronteiriça amapaense está diretamente ligada: aos movimentos de (des)construção e (des)territorialização; à grande atuação do Estado, embora seja fraca a fiscalização; à criação/construção de próteses dos mais variados modelos; à existência, configuração e intensidade de articulação das redes existentes, as quais expressam reflexos de cenários internacionais; às expectativas dos resultados da integração física com a Guiana Francesa; às suas restrições territoriais na faixa de fronteira (Figura 1); à posição desse território na economia-mundo como fornecedor de commodities e consumidor de produtos industrializados, situação esta que não é apenas característica da fronteira, mas sim de toda a região amazônica.

O que hoje se (re)conhece como a atual condição fronteiriça amapaense, portanto, seria resultado das tensões e contradições multiescalares existentes entre a própria realidade local-regional e o exercício da soberania do Brasil, profundamente permeadas por sistemas econômicos e redes geográficas das mais variadas.

Seguindo a linha de temas da atual agenda brasileira, deve-se lembrar que as próprias diretrizes da Política Nacional de Ordenamento Territorial

2 A IIRSA configura-se como um conjunto de redes técnicas, abarcando um sistema de logística (transporte multimodal com ênfase em rodovias e pontes binacionais, telecomunicações a partir da instalação de modernos equipamentos, hidroelétricas e gasodutos) entre os países signatários (SILVA, 2009). 
Jadson Luís Rebelo Porto • Gutemberg de Vilhena Silva

(PNOT) parecem estar em consonância com a construção de vínculos físicos transfronteiriços, de modo a ampliar a noção de ordenamento do território para uma macrovisão que englobe todo o território sul-americano. A questão das relações bilaterais e multilaterais com os países vizinhos - isto é, os temas transfronteiriços também fazem parte da pauta de uma política de ordenamento territorial no âmbito nacional, pois possuem importantes repercussões nos fluxos e mesmo em regiões às vezes distantes das fronteiras (RÜCKERT, 2007), o que motiva a análise sobre a condição fronteiriça das cidades amazônicas, dentre elas as do estado do Amapá.

Por outro lado, essa condição fronteiriça é marcada por acordos formais entre os territórios estatais fisicamente próximos e acordos informais entre as populações lá instaladas e em interação. Dessa forma, será abordada a seguir a relação entre o Programa Operacional Amazônia (POA, 2007), documento que estabelece as políticas econômicas e sociais da Guiana Francesa (França) com os países que com ela fazem fronteira, Suriname e Brasil, e as repercussões recentes na cooperação franco-brasileira no que diz respeito à biodiversidade e à pesquisa científica, frentes muito importantes do ponto de vista geopolítico.

\section{O PROGRAMA OPERACIONAL AMAZÔNIA E A COOPERAÇÃO NA FRONTEIRA FRANCO-BRASILEIRA}

O espaço de cooperação transfronteiriço amazônico é o tema do POA (2007) para um período de investimentos europeus (2007-2013) na Guiana Francesa, com o escopo de avançar a "Cooperação territorial européia" da política de coesão européia. Esse espaço apresenta fortes especificidades ligadas a sua situação única de cooperação transfronteiriça nas fronteiras exteriores terrestres da União Européia situadas fora do continente europeu. Isto tem motivado uma re-estruturação no uso do território amapaense, à medida que a aproximação transfronteiriça francesa com o Brasil tem evoluído a partir de 1995, estimulando esses novos usos. O acordo-quadro de cooperação assinado em 1995 entre a UE e o Mercosul foi um primeiro passo na preparação das negociações para a instauração da aproximação franco-brasileira para a fronteira, o que culminou com a assinatura de outro Acordo-Quadro, este agora especificamente entre Brasil e França, para funcionar como uma moldura institucional que pudesse favorecer a cooperação entre Amapá e Guiana Francesa.

A Lei de Orientação para o Ultramar (LOOM) n. 2000-1207, de 13 de dezembro de 2000, estabelece um papel importante para a cooperação regional, que se traduz na implementação de meios jurídicos e financeiros específicos (POA, 2007): 


\begin{tabular}{|c|c|}
\hline Meios financeiros & Meios jurídicos \\
\hline $\begin{array}{l}\text { A LOOM criou } 4 \text { Fundos de Cooperação Regio- } \\
\text { nal (FCR), um para cada DOM (Département } \\
\text { d'Outre- Mer), financiados por créditos do } \\
\text { Estado, podendo também receber doações do } \\
\text { Departamento, da Região ou de qualquer outra } \\
\text { coletividade ou organismo. } \\
\text { Sua implementação foi decidida pelo decreto no. } \\
2001-314 \text {, de } 11 \text { abril de } 2001 \text {, substituindo os } \\
\text { Fundos Interministeriais de Cooperação para as } \\
\text { Antilhas e a Guiana (FIC). } \\
\text { São elegíveis as ações de cooperação econômica, } \\
\text { social e cultural. } \\
\text { Um comitê fixa a lista das operações financiadas } \\
\text { por estes fundos e a taxa de subsídio aplicável } \\
\text { a cada uma delas, após consulta dos chefes dos } \\
\text { postos diplomáticos dos respectivos Estados. } \\
\text { Os FCR são em princípio destinados a colaborar } \\
\text { apenas em co-financiamento com os cndidatos } \\
\text { dos projetos. }\end{array}$ & $\begin{array}{l}\text { Os artigos } 42 \text { e } 43 \text { da LOOM autorizam a } \\
\text { descentralização das decisões em matéria de } \\
\text { cooperação regional, sem que seja modificada a } \\
\text { responsabilidade da politica externa da França, } \\
\text { a qual continua confiada ao Estado. Cada DOM } \\
\text { pode enviar ao governo suas propostas tendo em } \\
\text { vista a realização de acordos internacionais refe- } \\
\text { rentes à cooperação regional entre a França e os } \\
\text { contribuidores para esses fundos; os presidentes } \\
\text { do Conselho Geral e do Conselho Regional estão } \\
\text { habilitados a negociar acordos internacionais } \\
\text { (enquanto representantes do Estado) ou a estar } \\
\text { associados às negociações. Nos domínios de } \\
\text { competência dos departamentos e das regiões, } \\
\text { os conselhos podem pedir às autoridades da } \\
\text { República a autorização para seus presidentes } \\
\text { negociarem e assinarem acordos internacionais. }\end{array}$ \\
\hline
\end{tabular}

(PROGRAMMEDE COOPERATION TRANSFRONTALIERE. AMAZONIE, 2008).

Os FCR são um dos instrumentos principais da cooperação regional do Estado Francês e das coletividades territoriais desse país para as ações de cooperação, em conexão com os programas dos diferentes postos diplomáticos. Os FCR contribuem para a inserção de Guadalupe, da Martinica e da Guiana Francesa no espaço geográfico francês, participando das ações de cooperação econômica, social e cultural com os demais países da região. Intervêm em cofinanciamento com as contribuições externas e permitem que os DFA se envolvam totalmente, com toda responsabilidade, numa dinâmica de integração regional em várias áreas estratégicas como a biodiversidade e a parceria em pesquisas científicas.

\subsection{Biodiversidade e pesquisa}

A biodiversidade representa um aspecto do meio ambiente que é caracterizado por forte influência da globalização (FEARNSIDE, 2002). Desse modo, a maior parte dos projetos não comerciais de cooperação transfronteiriça tem como tema a pesquisa científica, em especial nos domínios da biodiversidade amazônica.

Um memorando foi assinado entre o Ministro do Meio Ambiente do Brasil (MMA) e o Ministro da Ecologia e do Desenvolvimento Sustentável da França (Ministère de l'Ecologie et du Développement Durable - MEDD), em 16 de outubro 
Jadson Luís Rebelo Porto • Gutemberg de Vilhena Silva

de 2004, cujo objetivo central foi permitir o reforço das cooperações regionais, em particular, em matéria de biodiversidade e de preservação do patrimônio florestal.

Além disso, o projeto de cooperação em gestão florestal sustentável entre a Guiana Francesa, o Amapá, o Amazonas e o Pará (início em 2004), intitulado SILMANET e apoiado pelo Ofício Nacional de Florestas (ONF) da França, demonstra plenamente a vontade de aprofundar a cooperação transfronteiriça entre França e Brasil no campo da biodiversidade. Reunindo parceiros franceses, tais como o Centro de Cooperação Internacional em Pesquisa Agronômica para o Desenvolvimento (Centre de Coopération Internationale en Recherche Agronomique pour le Développement- CIRAD), o Sistema de Informações Geográficas (Geographic Information System - GIS) SILVOLAB ${ }^{3}$, a Câmara de Comércio e Indústria da Guiana Francesa (Chambre de Commerce et d'Industrie de la Guyane (CCIG), a Região da Guiana Francesa ${ }^{4}$ e o Conselho Geral Guianense) e parceiros brasileiros (entre os quais o Instituto Brasileiro de Recursos Naturais (IBAMA) bem como a Empresa Brasileira de pesquisa Agropecuária (EMBRAPA) e a Universidade Rural da Amazônia (UFRA), esse projeto, financiado pelo FCR, tem como objetivo identificar as instituições que intervêm no domínio da floresta e dos produtos florestais, tendo em vista sua inclusão na rede e a distinção dos eixos de cooperação técnica que possam ser propostos para a obtenção de financiamento de programas de cooperação regional (Interreg, FCR, etc.).

Vários outros projetos vêm sendo elaborados ou realizados em colaboração com o Brasil:

- na área da epidemiologia e luta biológica, o trabalho com a mosca-da-carambola, realizado em associação entre a CIRAD e a Universidade de São Paulo. Um acordo franco-brasileiro de vigilância epidemiológica relativa aos dois lados do rio Oiapoque motivou missões mensais do CIRAD na zona de fronteira;

- $\mathrm{o}$ treinamento de agentes da Polícia Federal pela ONCFS (em fase de elaboração) para o combate ao tráfico internacional de fauna selvagem;

- na área da gestão de espaços naturais: criação, em 2003, de um comitê de cooperação franco-brasileira associando o Parque Nacional das Montanhas do Tumucumaque e o Parque Nacional da Guiana.

Ademais, a iniciativa Interreg-III visa a constituição de uma base de consonância e de trocas de negócios entre a Guiana Francesa e o Estado do Amapá,

3 Na Guiana Francesa, o Silvolab congrega dez instituições de pesquisa, educação e manejo florestal; enquanto no Brasil o Ecolab, programa franco-brasileiro, promove a cooperação técnico-científica na área de ecossistemas costeiros da Amazônia.

4 Corresponde, grosso modo, ao "Governo Estadual" no Brasil, embora também tenha poderes legislativos. 
com informações relativas às legislações e às regulamentações das áreas protegidas, da exploração da floresta, da pesca, da atividade mineral e da biopirataria, bem como informações sobre o domínio econômico, cultural, esportivo e tecnológico.

Em artigo recente, Silva e Porto (no prelo) apresentaram a hipótese de que as relações entre Brasil e França no que concerne à biodiversidade com foco na fronteira evidenciam que, do ponto de vista econômico, as políticas implementadas em ambientes periféricos estão reforçando a lógica desigual do controle da informação e da gestão estratégica do território, o que no caso amazônico é bastante significativo pelo peso geopolítico que a França possui. No artigo em questão, foram desenvolvidas reflexões em torno da criação do Centro Franco-Brasileiro da Biodiversidade Amazônica (CFBBA).

De um modo geral, o CFBBA será constituído por núcleos de pesquisa dos dois países, estabelecidos de comum acordo e articulados para utilizar a infraestrutura técnica de seus territórios nacionais a fim de promover interações espaciais no campo técnico-científico e executar projetos conjuntos no campo da biodiversidade. A proposta levará em consideração a Convenção sobre Diversidade Biológica $\left(\mathrm{CDB}^{5}\right)$ de que os dois países são signatários.

O CFBBA objetiva também formar mais especialistas em biodiversidade amazônica, bem como possibilitar o desenvolvimento das pesquisas de recursos genéticos do bioma e o acesso aos conhecimentos tradicionais e o desenvolvimento de produtos. Interessa mencionar que a manutenção de estoques genéticos também tem interesse para usos ainda não desenvolvidos ou descobertos. Sobre esse assunto, FEARNSIDE (2002, p. 172) aponta que é fundamental

o papel de organismos naturais como fonte de informações para direcionar a fabricação de novos fármacos, exploração cujo valor para a humanidade é maior do que a já considerável quantia de dinheiro movimentada pelas empresas farmacêuticas no mundo.

- à perenidade do patrimônio natural comum que constitui uma riqueza compartilhada, em que a proteção (prevenção dos riscos de poluição e proteção da biodiversidade) constitui um interesse primordial e uma condição indispensável para uma valorização duradoura de recursos naturais, do mesmo modo que

5 A Convenção sobre Diversidade Biológica - CDB é um dos principais resultados da Conferência das Nações Unidas para o Meio Ambiente e o Desenvolvimento - CNUMAD (Rio 92), realizada no Rio de Janeiro, em junho de 1992. É um dos mais importantes instrumentos internacionais relacionados ao meio ambiente e funciona como um guarda-chuva legal/político para diversas convenções e acordos ambientais mais específicos. A CDB é o principal fórum mundial na definição do marco legal e político para temas e questões relacionados à biodiversidade (168 países assinaram a CDB e 188 países já a ratificaram, tendo estes últimos se tornado Parte da Convenção) (cf. <http://www.cdb.gov.br/CDB>). 
Jadson Luís Rebelo Porto • Gutemberg de Vilhena Silva

a conservação e a valorização dos conhecimentos e saberes tradicionais, que constituem igualmente uma herança comum;

- ao reforço dos equilíbrios internos das sociedades que são, cada uma, marcada por uma extrema juventude e o caráter multicultural de sua população, passando pelo desenvolvimento (quantitativo e qualitativo) da oferta de educação e do diálogo intercultural;

- ao desenvolvimento da atratividade e da competitividade, passando designadamente por determinadas atividades baseadas na valorização de potencialidades comuns. Para essas atividades, uma abordagem comum pode ter um efeito diluidor, em termos de imagem, o que torna possíveis as economias de escala (turismo, produções locais, pesquisa...);

- ao ordenamento e ao desenvolvimento dos espaços fronteiriços, sobretudo urbanos, que apelam ao conhecimento de mutações profundas, considerando-se o crescimento dos fluxos de deslocamento e de intercâmbios que acompanharão a implementação de uma rede internacional de vias terrestres de comunicação.

\section{CONCLUSÃO}

As recentes mudanças ocorridas no espaço amapaense, desde meados da década de 1990, indicam a construção de novos usos desse território e de mudanças na sua condição fronteiriça. Por outro lado, a conexão fronteiriça entre Brasil e França tem estimulado muito mais um processo de interação do que de integração econômica, sob a perspectiva da fronteira-rede, haja vista que o interesse maior das macropolíticas elaboradas por agentes nacionais e internacionais objetivam a ativação de apenas alguns pontos nesse novo uso do território amapaense.

De todo modo, é evidente que, de uma forma ampla, as resistências geopolíticas decorrentes de receios expansionistas, que caracterizaram a Geopolítica Clássica de reprodução dos Estados Nacionais, vêm, gradativamente, sendo substituídas pela busca de cooperações nas mais diversas escalas em territórios como o sul-americano.

O entendimento da fronteira como espaço de oportunidades e de conflitos, com múltiplos tipos de ação e de tempos, envolve, por consequência, múltiplos atores e níveis de decisão. Essas características tornam mais complexas as análises sobre a fronteira e suas condições.

No caso amapaense, a construção do território deve levar em conta três condições: a fronteiriça, a urbana e a ambiental. Neste trabalho, privilegiamos a primeira. Mas é importante notar que, de uma forma mais geral, as três foram estimuladas de forma acentuada no último decênio do século XX, em função das novas dinâmicas territoriais criadas com as Unidades de Conservação e Terras Indígenas, 
no domínio ambiental, da migração permanente para o norte amapaense, no que diz respeito ao urbano e, principalmente, pelo fato de se pensar a fronteira como fronteira-rede e como lócus de inúmeras propostas de cooperação transfronteiriça com a Guiana Francesa.

Assim, pode-se concluir que a atual condição fronteiriça amapaense é resultado das tensões e contradições multiescalares existentes entre a realidade local-regional e o exercício da soberania dos Estados nacionais, profundamente permeadas por sistemas econômicos e redes geográficas das mais variadas. É também marcada por acordos formais entre os territórios estatais próximos fisicamente e acordos informais entre as populações lá instaladas e que estão em interação.

Em relação ao Programa Operacional Amazônia, sumariamente destacado no presente trabalho, é perceptível a preocupação francesa em estabelecer laços com seu vizinho sul-americano com o intuito de reafirmar sua presença neste subcontinente, estimulando outras interações espaciais em diversas escalas de gestão e participação. Por fim, é importante notar que o espaço de cooperação é fortemente marcado por assimetrias, pelas diferenças em termos de situação socioeconômica e por um crescimento de influência, em um contexto de desenvolvimento programado, dos intercâmbios comerciais claramente visualizados no Programa Operacional Amazônia proposto pela União Européia.

\section{REFERÊNCIAS}

ARBARET-SCHULZ, C. et. al. La frontière, un objet spatial en mutation. EspacesTemps.net, 2004. Disponível em: http://espacestemps.net/document842. html. Acesso em: 15 set 2006.

BRASIL. Ministério da Integração. Proposta de reestruturação do Programa de Desenvolvimento da Faixa de Fronteira: bases de uma política integrada de desenvolvimento regional para a faixa de fronteira. Brasília, 2005.

BRITO, Daguinete M. C. A construção do espaço público na gestão de unidades de conservação: o caso da APA do Rio Curiaú/AP. 2003. 172 f. Dissertação (Mestrado em Desenvolvimento Sustentável). Orientador: José A. Drummont - CDS/UNB/Universidade Federal do Amapá, Macapá, 2003.

CORRÊA, R. L. Interações Espaciais. In: CASTRO, I. E.; GOMES, P. C. C.; CORRÊA, R. L. Explorações geográficas. Rio de Janeiro: Bertrand Brasil, 1996. 
Jadson Luís Rebelo Porto • Gutemberg de Vilhena Silva

FEARNSIDE, P. M. A globalização do meio-ambiente: o papel da Amazônia brasileira. Boletim do Museu Paraense Emilio Goeldi, Belém, v. 18, n. 2, p. 167-181, mês abr. 2002

FLORES, Mário Cesar. Defesa Nacional na ordem do século XXI. In: CENTRO BRASILEIRO DE RELAÇÕES INTERNACIONAIS. Dossiê CEBRI, v. 1, ano 2, 2003.

FOUCHER, M. Fronts et frontières: un tour du monde géopolitique. Paris: Fayard, 1991.

JESSOP, B. La economia política de la escala y la construcción de las regiones transfronterizas. Eure, Santiago, v. 30, n. 89, p. 25-41, maio 2004.

LIMA, Ricardo Ângelo Pereira de. Antropizacion, dinámicas de ocupación del territorio y desarrollo en la Amazonia Brasileña: el caso del Estado de Amapá. 2004. 250 f. Tese (Doutorado em Geografia Humana) - Universitat Autònoma de Barcelona, Barcelona, 2004.

LIMA, R. A. P.; PORTO, J. L. R. Ordenamento territorial amapaense: dinâmicas de um estado brasileiro na fronteira amazônica. In: X COLOQUIO INTERNACIONAL DE GEOCRÍTICA, Unidad de Barcelona, 26-30 de mayo de 2008. Disponíveis em: <http://www.ub.es/geocrit/-xcol/100.htm>. Acesso em 23 de maio de 2009.

MACHADO, L. O. Ciência, tecnologia e desenvolvimento na faixa de fronteira do Brasil. Parcerias estratégicas, Belém, n. 20, p. 747-766, jun 2005.

PORTO, Jadson Luís Rebelo. Amapá: principais transformações econômicas e institucionais - 1943 a 2000. Macapá: SETEC, 2003.

(Re)construções amapaenses: 60 anos de transformações espaciais. Macapá: Jadson Porto, 2006. (Série Percepções do Amapá; v. 4).

PROGRAMME DE COOPERATION TRANSFRONTALIERE. AMAZONIE. (2007-2013). POA - Programa Operacional Amazônia. Document de travail. Version 17 août 2007. Disponível em: <www.cr-guyane.fr/ressources/File/eservices/POGuyane.pdf>. Acesso em: 20 nov. 2008.

RÜCKERT, A. A. A política nacional de ordenamento territorial-Brasil: uma política territorial contemporânea em construção. In: Scripta Nova. Revista eletrônica de Geografia y Ciencias Sociales. Barcelona: Unidade de Barcelona, 1 de agosto de 2007. v. XI, n. 245 (66). [ISSN: 1138-9788]. Disponível em: <http:// www.ub.es/geocrit/sn/sn-24566.htm. Acesso em 15 de agosto de 2008. 
[SILVA, G. V. Novos usos territoriais da fronteira Franco-Brasileira. In: PORTO, J.; CHELALA A., C.; SILVA, G.V.; COUTO, M.E.A.. (Org.). Condicionantes construídos: reflexões sobre as transformações espaciais amapaenses. Macapá: Jadson Porto, 2007.

Usos contemporâneos da fronteira franco-brasileira: entre os ditames globais e as articulações locais. 2008. 175 f. Dissertação (Mestrado em Geografia) - Instituto de Geociências. Universidade Federal do Rio Grande do Sul. Porto Alegre, 2008.

Integração Física Sul-Americana: Redes técnicas, território e escalas de ação no Planalto das Guianas. In: CARVALHO, G.; WAGNER, Alfredo. (Org.). O Plano IIRSA na visão da Sociedade Civil Pan-Amazônica. Belém: FASE; Observatório Comova/UFPA, 2009, p. 213-248.

SILVA, G. V.; RÜCKERT, A. A. Processos contemporâneos de usos da fronteira franco-brasileira. In: ARAGÓN, L; OLIVEIRA, J. A. (Org.). Amazônia no cenário sul-americano. Manaus: EDUFAM, 2009, p. 333-346.

SILVA, G. V.; PORTO, J. L. R. Interações espaciais entre territórios periféricos no Norte da América do Sul. Revista Percurso, Curitiba. No prelo. 